\title{
Correction to: Offline simulation of path deviation due to joint compliance and hysteresis for robot machining
}

\author{
Marcel Cordes ${ }^{1} \cdot$ Lukas Brunke $^{1} \cdot$ Wolfgang Hintze $^{1}$ \\ Published online: 4 November 2019 \\ (C) Springer-Verlag London Ltd., part of Springer Nature 2019
}

Correction to: The International Journal of Advanced Manufacturing Technology https://doi.org/10.1007/s00170-016-9461-z

The name of one author was omitted in the initially published version.

The correct list of authors is Marcel Cordes, Lukas Brunke, and Wolfgang Hintze.

The online version of the original article can be found at https://oi.org/ 10.1007/s00170-016-9461-z

Marcel Cordes

marcel.cordes@tuhh.de

Institute of Production Management and Technology, Hamburg

University of Technology, 21073 Hamburg, Germany 